\title{
Bioequivalence Evaluation of a Combine Formulation of Pioglitazone/ Metformin in Healthy Pakistani Volunteers
}

\author{
Mateen Abbas*, Sualeha Riffat, Abdul Muqeet Khan and Muhammad Nawaz \\ Bioequivalence Study (BeSt) Centre, Institute of Pharmaceutical Sciences, University of Veterinary and Animal Sciences (UVAS), Lahore, Pakistan
}

\begin{abstract}
The purpose of this study was to evaluate bioequivalence of a combine formulation of pioglitazone/metformin $15 / 850 \mathrm{mg}$ tablet with those of an established branded formulation. An open-label, single-dose, randomized, 2-way crossover study was conducted in fasted healthy Pakistani male volunteers. The concentrations of pioglitazone and metformin in plasma were analyzed by reverse phase High Performance Liquid Chromatography (HPLC). The plasma concentration-time curves were used to obtain pharmacokinetic parameters including $A_{U} C_{0-t}, A C_{0-\infty}$, and $C_{\max }$. The formulations were considered bioequivalent if the $90 \%$ confidence intervals (Cls) for AUC, and $C_{\max }$ fell within the interval of $80 \%$ to $125 \%$, declared in bioequivalence guidelines. On analysis of variance, no period, formulation or sequence effects were observed for any pharmacokinetic property. The $90 \%$ confidence intervals of pioglitazone for the geometric mean ratios of $\mathrm{C}_{\max }, \mathrm{AUC}_{0-\mathrm{t}}$ and $\mathrm{AUC}_{0-\infty}$ were $93.34 \%$ to $103.12 \%, 86.15 \%$ to $106.03 \%$ and $85.62 \%$ to $107.41 \%$, respectively. Similarly, the $90 \%$ Cls of metformin for the geometric mean ratios of $\mathrm{C}_{\text {max }}$, $\mathrm{AUC}_{0-\mathrm{t}}$ and $\mathrm{AUC}_{0-\infty}$ were $87.64 \%$ to $100.85 \%, 86.68 \%$ to 116.15 and $94.14 \%$ to $122.71 \%$, respectively, qualifying the predetermined criteria for bioequivalence based on the rate and extent of absorption.
\end{abstract}

Keywords: Bioequivalence; pharmacokinetics; Pioglitazone; Metformin; HPLC

\section{Introduction}

Numerous oral antidiabetic drugs with different mechanisms of action have been developed to lower glucose and delay the occurrence of serious complications in patients with type 2diabetes [1]. For glycemic control in diabetic patients, monotherapy with an oral antidiabetic agent is not adequate to achieve satisfactory blood glucose control [2]. Thus, combination regimens which include drugs with different and complementary mechanisms of action are recommended for achieving satisfactory blood glucose levels [3-7]. Hypoglycemic agents such as metformin, glipizide, glyburide, repaglinide, rosiglitazone, nateglinide, and pioglitazone are widely prescribed to control blood sugar levels. The majority of combination medicines available to date are based on metformin co-administration.

Therapeutic drug monitoring necessitates the measurement of their plasma concentration for studying the pharmacokinetics of these drugs, assessment of bioequivalence of commercially available tablet formulation and for optimization of dosing in combination therapy $[2,8]$.

The public health care is very expensive in Pakistan due to high cost of prescribed medicine of multinational products. An extensive research to monitor the quality of generic drugs of national pharmaceutical companies may reduce the price significantly. To comply with the regulatory requirements of Pakistan, the relative bioavailability of a pioglitazone/metformin drug product, already marketed in Pakistan, had to be compared with an innovator product. Therefore, the main objective of this study was to assess the bioequivalence of two pioglitazone/metformin 15/850 $\mathrm{mg}$ tablets in healthy adult male Pakistani volunteers to achieve the goal of accessibility of medicine to a common man.

\section{Materials and Methods}

\section{Chemicals and reagents}

Pioglitazone (99.9 \%) and metformin (99.4\%) were generously provided by local purveyor Hilton Pharmaceutical (Pvt) Ltd, Karachi.
Blood samples from drug free volunteers were collected, separated plasma and stored at $-20^{\circ} \mathrm{C}$ till further use.

\section{Study design}

This was an open-label, single-dose, randomized, 2-way crossover bioequivalence study with 10 days washout period between each administration. Each volunteer received a single dose of either the test or reference formulation of 15/850 $\mathrm{mg}$ pioglitazone/metformin, in random order based on computer-generated tables of random numbers.

\section{Calibration standards and quality control}

Two samples of $(10 \mathrm{mg})$ pioglitazone and metformin were dissolved in distilled water in two separate $100 \mathrm{ml}$ volumetric flasks to give standard stock solution of $100 \mu \mathrm{g} / \mathrm{ml}$. Calibration standards were prepared in human plasma by spiking a known amount of pioglitazone and metformin to control plasma (drug-free) samples to produce standards with final concentrations of $0.25,0.5,0.6,0.8,1.0$ and $1.2 \mu \mathrm{g} / \mathrm{ml}$. Calibration curves were generated by measuring the detector response as peak-area versus concentration of the drug. The accuracy and precision were assessed by measuring the intraday and interday coefficient of variation $(\mathrm{CV})$ at different quality control $(\mathrm{QC})$ concentrations: low, medium and high $(0.55,0.9$ and $1.1 \mu \mathrm{g} / \mathrm{ml})$.

\section{Instrumentation and chromatographic conditions}

Pioglitazone and metformin in the plasma samples were analyzed

*Corresponding author: Mateen Abbas, Bioequivalence Study (BeSt) Centre Institute of Pharmaceutical Sciences, University of Veterinary and Animal Sciences (UVAS), Lahore, Pakistan. Tel: +92-3336546452; E-mail: Hafizmateen2002@ yahoo.com

Received April 07, 2011; Accepted June 22, 2011; Published June 24, 2011

Citation: Abbas M, Riffat S, Khan AM, Nawaz M (2011) Bioequivalence Evaluation of a Combine Formulation of Pioglitazone/Metformin in Healthy Pakistan Volunteers. J Bioequiv Availab 3: 092-096. doi:10.4172/jbb.1000066

Copyright: $\odot 2011$ Abbas M, et al. This is an open-access article distributed unde the terms of the Creative Commons Attribution License, which permits unrestricted use, distribution, and reproduction in any medium, provided the original author and source are credited. 
by HPLC methods with some modifications of already developed methods $[9,10]$. The analysis was performed on a chromatographic system Shimadzu SP-20, Japan. The analytical columns used to achieve chromatographic separation were Merck C-18, $(250 \times 4.6) \mathrm{mm} ; 5 \mu \mathrm{m}$, for pioglitazone and MetaSil-Phenyl column $(250 \mathrm{x} 4.6) \mathrm{mm}, 5 \mu \mathrm{m}$ for metformin. The mobile phase for pioglitazone comprised of acetonitrile: $1.36 \%$ disodium hydrogen phosphate $(35: 65, \mathrm{v} / \mathrm{v})$, adjusted to $\mathrm{pH} 7.0$ with ortho phosphoric acid. The mobile phase for metformin consist of acetonitrile: $0.02 \mathrm{M}$ sodium dihydrogen phosphate $(50: 50 \mathrm{v} / \mathrm{v})$, adjusted to $\mathrm{pH} 7.0$ with ortho phosphoric acid. Analysis was run at flow-rate of $1 \mathrm{ml} / \mathrm{min}$ at $40^{\circ} \mathrm{C}$ on wavelength of $236 \mathrm{~nm}$.

\section{Sample preparation}

For pioglitazone: One $\mathrm{ml}$ of plasma and $2 \mathrm{ml}$ of acetonitrile (ACN):trifluoro acetic acid (1\%) solution with a ratio of $(85: 15)$ was added into a $10 \mathrm{ml}$ glass tube, vortexed for 3 minute and centrifuged (Hettich EBA 21, Germany) at 10,000 rpm for $10 \mathrm{~min}$. Aspirate the upper layer and dry it under water bath. Five hundred (500) $\mu \mathrm{l}$ of mobile phase was added to the tube, vortexed for 3 minutes. The sample filtered by 0.2 micron syringe filter and transferred into an auto-sampler vial (Millipore, MA, USA), and $75 \mu \mathrm{L}$ was subsequently injected into HPLC system.

For metformin: One $\mathrm{ml}$ of plasma sample and $50 \mu \mathrm{L}$ of $0.05 \mathrm{M}$ Hydrochloric acid $(\mathrm{HCl})$ were added and vortexed for 3 minutes. For protein precipitation $2 \mathrm{ml}$ of ACN was added and the mixture was centrifuged (Hettich EBA 21, Germany) at 10,000 rpm for 10 minutes. The supernatant was dried under nitrogen stream and the extract was reconstituted with $500 \mu \mathrm{L}$ mobile phase and $75 \mu \mathrm{L}$ was injected into chromatographic system.

\section{Assay validation}

Assay validation was performed according to the FDA guidance for industrial bioanalytical method validation [11]. Linearity was determined using a linear least-squares regression of the six human plasma standards. The sensitivity of the method was expressed as the lower limit of quantification (LLOQ) that could be quantitatively determined with acceptable accuracy and precision. The accuracy and precision were assessed by analyzing six concentrations of QC samples.

\section{Pharmacokinetic and bioequivalence studies in healthy volunteers}

A randomized, single-dose, two-period, two-sequence, and crossover design was used for the assessment of the pharmacokinetics and bioequivalence. The study was conducted at the Bioequivalence Study (BeSt) Centre. Drug was randomly given to 24 healthy volunteers under a registered physician. The study was carried out according to principles of good clinical practice (GCP) keeping in view the national legal requirements, the ICH Harmonized Tripartite Guideline for GCP and the ethical principles laid down in the Declaration of Helsinki. Based on this description, they provided written informed consent before participating in the study. The Institutional Review Board of University of Veterinary and Animal Sciences (UVAS) approved the protocol prior to initiate the trial.

Twenty-four volunteers aged between 20-33 years $(23.0 \pm 3.2$ years), with a height between 151-179 $\mathrm{cm}(170.25 \pm 6.98 \mathrm{~cm})$ and with body weights between $50-77 \mathrm{~kg}(61.50 \pm 8.04 \mathrm{~kg})$ were assessed as having a healthy status by clinical evaluations. After an overnight fasting of at least 12 hours, subject were randomized to receive test dose a Tablet Piozer Plus ${ }^{\oplus}$ (Hilton Pharmaceutical (pvt) Ltd., Pakistan) and equivalent oral doses of Competact ${ }^{\star}$ (Takeda Institute, Japan) Tablet $15 / 850 \mathrm{mg}$ with $240 \mathrm{ml}$ of water followed by $60 \mathrm{ml}$ of the glucose solution administered every 15 minutes up to 4 hours after the initial intake dose. Twelve days post administration was considered as a washout period and the subjects were readmitted and received the alternate treatments according to their randomization for treatment sequence. Prior to drugs administration, a control/blank blood sample was collected from each subject. Following drug administration, $8 \mathrm{ml}$ blood samples from each were drawn at $0.25,0.5,1.0,1.5,2.0,2.5,3.0$, $3.5,4.0,6.0,8.0,10,12,24,48$ and 72 hours. The blood samples were centrifuged (Hettich EBA 21, Germany) at 10,000 rpm for $10 \mathrm{~min}$ at room temperature and plasma was stored at $-80^{\circ} \mathrm{C}$ till further use.

\section{Software}

Pharmacokinetic parameters such as Cmax, Tmax, Elim. rate constant, Half_life $\mathrm{AUC}_{0-\mathrm{t}}, \mathrm{AUC}_{0-\infty}, \mathrm{AUMC}_{0-\mathrm{t}}$ and $\mathrm{AUMC}_{0-\infty}$, were calculated by EquivTest $\mathrm{PK}$ software. After logarithmic transformation of the data, $\mathrm{C}_{\max }, \mathrm{AUC}_{0-\mathrm{t}}$ and $\mathrm{AUMC}_{0-\mathrm{t}}$ values were subjected to ANOVA for a $2 \times 2$ crossover design to assess effects due to periods, formulation, and sequence using an $\mathrm{F}$ test; $\mathrm{P}<0.05$ was considered significant.

\section{Statistical analysis}

The $90 \%$ confidence interval (CI) and geometric mean ratio between the two products was calculated by using EquiTest PK

\begin{tabular}{|l|l|l|l|l|}
\hline \multirow{2}{*}{ Nominal concentration $(\mu \mathrm{g} / \mathrm{mL})$} & \multicolumn{4}{|c|}{ Precision $(\mathrm{RSD} \%)^{*}$} \\
\hline & \multicolumn{4}{|c|}{ Intraday } \\
\cline { 2 - 6 } & $\mathrm{P}^{1}$ & $\mathrm{M}^{2}$ & $\mathrm{P}$ & $\mathrm{M}$ \\
\hline 0.55 & 1.17 & 0.91 & 1.3 & 1.96 \\
\hline 0.9 & 0.96 & 0.86 & 0.93 & 1.74 \\
\hline 1.1 & 0.68 & 0.46 & 0.29 & 0.4 \\
\hline
\end{tabular}

${ }^{*} \mathrm{RSD}=$ Relative standard deviation, ${ }^{1} \mathrm{P}=$ Pioglitazone, ${ }^{2} \mathrm{M}=$ Metformin

Table 1: Intraday and interday Precision for analysis of pioglitazone and metformin in human plasma $(n=6)$.

\begin{tabular}{|c|c|c|c|c|}
\hline $\begin{array}{l}\text { Amount of } \\
\text { Drug added } \\
(\mu \mathrm{g} / \mathrm{ml})\end{array}$ & $\begin{array}{l}\text { Amount of Pioglitazone } \\
\text { found }(\mu \mathrm{g} / \mathrm{ml})\end{array}$ & Accuracy & $\begin{array}{l}\text { Amount of Metformin } \\
\text { found }(\mu \mathrm{g} / \mathrm{ml})\end{array}$ & Accuracy \\
\hline \multirow{6}{*}{0.55} & 0.56 & 102.39 & 0.58 & 104.98 \\
\hline & 0.56 & 102.52 & 0.58 & 105.09 \\
\hline & 0.56 & 102.30 & 0.58 & 105.98 \\
\hline & 0.56 & 102.50 & 0.58 & 105.36 \\
\hline & 0.56 & 102.66 & 0.58 & 105.57 \\
\hline & 0.57 & 102.77 & 0.57 & 104.14 \\
\hline Average & & 102.52 & & 105.19 \\
\hline \multirow{6}{*}{0.9} & 0.88 & 98.14 & 0.88 & 97.40 \\
\hline & 0.88 & 97.81 & 0.88 & 98.22 \\
\hline & 0.88 & 97.74 & 0.88 & 97.62 \\
\hline & 0.89 & 99.02 & 0.88 & 97.57 \\
\hline & 0.88 & 97.92 & 0.88 & 97.60 \\
\hline & 0.88 & 97.25 & 0.87 & 96.25 \\
\hline Average & & 97.98 & & 97.45 \\
\hline \multirow{6}{*}{1.1} & 1.06 & 96.10 & 1.11 & 100.77 \\
\hline & 1.06 & 96.41 & 1.10 & 99.93 \\
\hline & 1.06 & 96.28 & 1.09 & 98.95 \\
\hline & 1.05 & 95.72 & 1.09 & 99.08 \\
\hline & 1.05 & 95.79 & 1.08 & 98.49 \\
\hline & 1.06 & 96.29 & 1.11 & 100.56 \\
\hline Average & & 96.10 & & 99.63 \\
\hline
\end{tabular}

Table 2: Accuracy of pioglitazone and metformin in human plasma $(n=6)$. 


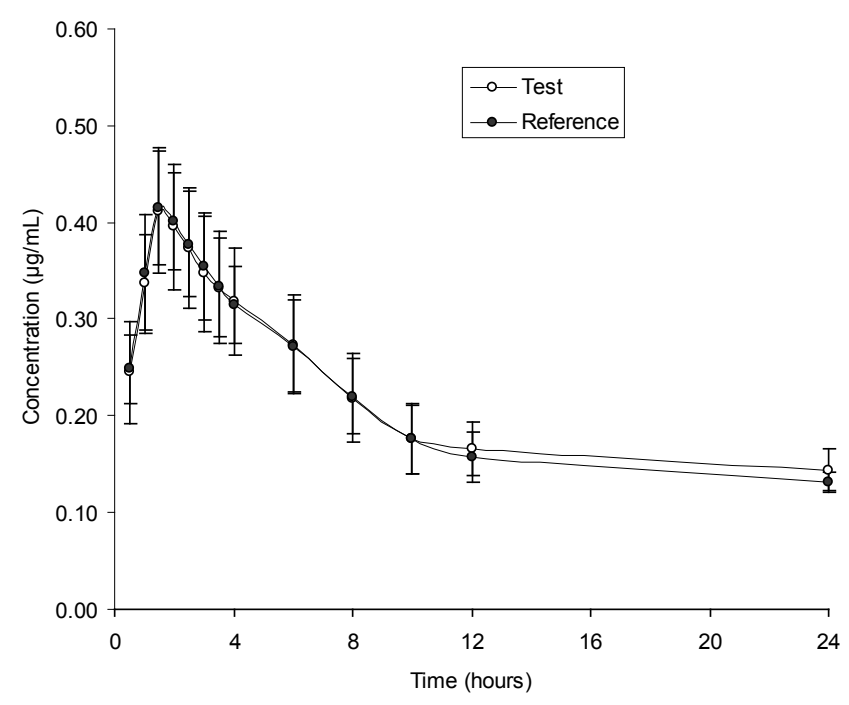

Figure 1: Pioglitazone plasma concentration-time profiles after administration of a single $15 / 850 \mathrm{mg}$ dose of 2 formulations of pioglitazone/metformin in 24 healthy Pakistani male volunteers.

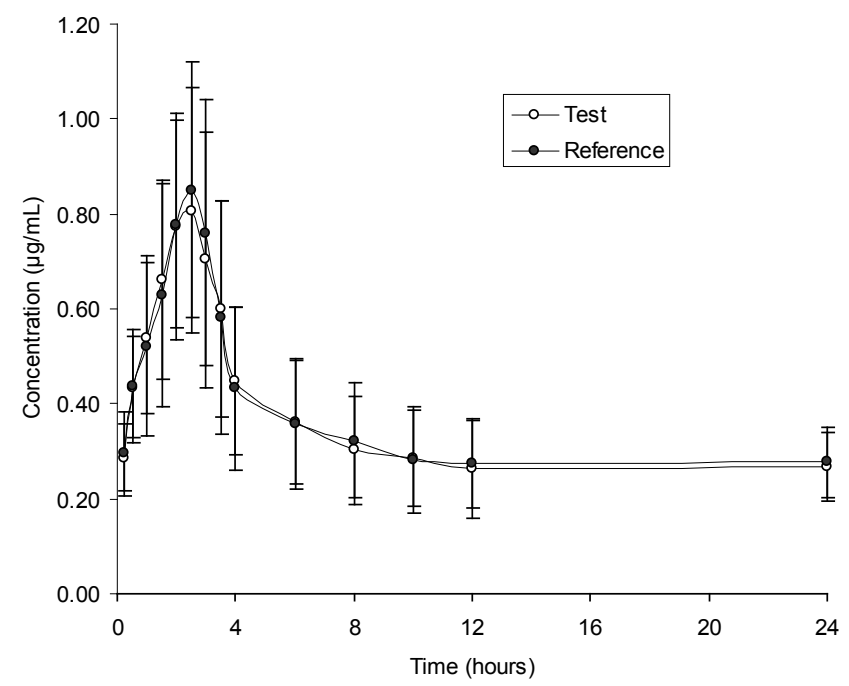

Figure 2: Metformin plasma concentration-time profiles after administration of a single $15 / 850 \mathrm{mg}$ dose of 2 formulations of pioglitazone/metformin in 24 healthy Pakistani male volunteers.

software. Analysis of variance (ANOVA) was used to check the period, sequence and formulation effect of test and reference.

\section{Results}

\section{Separation of drugs}

A routine preparation procedure like the extraction, evaporation and reconstitution with the mobile phase were used before reverse phase HPLC separation. No significant endogenous peaks at the retention time of pioglitazone or metformin was recorded using blank sample of human plasma. The retention times of pioglitazone and metformin were 6.4 and $3.8 \mathrm{~min}$, respectively.

\section{Method validation}

The results indicated that the validation procedure modified in this experiment showed good precision and accuracy for both drugs. The standard calibration curves of both drugs showed good linearity within the range of 0.5 to $1.2 \mu \mathrm{g} / \mathrm{ml}$ in human plasma ( $\mathrm{y}=245886 \mathrm{x}+14512$, $\left.r^{2} \geq 0.9979\right)$ for pioglitazone and $\left(y=320849 x+21224, r^{2} \geq 0.9971\right)$ for metformin. Intraday and interday precisions and accuracies were determined by analyzing QC samples against a calibration curve, on the same day $(n=6)$ and on different days $(n=6)$. This method allowed good precision and accuracy for both drugs and the coefficient of variation values for pioglitazone of both intraday and interday results were below $1.17 \%$ and $1.30 \%$ (Table 1), respectively and accuracy was $96.10 \%-102.52 \%$ (Table 2). Similarly the coefficient of variation values for metformin of both intraday and interday results were below $0.91 \%$ and $1.96 \%$ (Table 1), respectively and accuracy was $97.45 \%-105.19 \%$ (Table 2).

\section{Tolerability}

Neither major nor minor clinical adverse affects were observed during the entire study period. All participants were available during the study period and three week post study period.

\section{Pharmacokinetic Analysis}

The mean plasma concentration-time curves of 2 formulations of pioglitazone is shown in Figure 1. The primary PK parameters for both drugs are listed in Table 3. The mean (SD) $\mathrm{C}_{\max }$ values of the test and reference formulations of pioglitazone were $0.41(0.07)$ and $0.42(0.06)$ $\mu \mathrm{g} / \mathrm{ml}$, respectively and the mean $(\mathrm{SD}) \mathrm{T}_{\max }$ values were $0.90(0.25)$ and 1.04 (0.41) hours, respectively. Results for the extent of absorption, as determined from mean (SD) $\mathrm{AUC}_{0-\mathrm{t}}$ and $\mathrm{AUMC}_{0-\mathrm{t}}$ values, were 3.13 (1.03) and 17.58 (12.15) $\mu \mathrm{g} . \mathrm{h} / \mathrm{ml}$ respectively, after administration of the test formulation; and 3.28 (1.08) and 19.98 (14.54) $\mu \mathrm{g} . \mathrm{h} / \mathrm{ml}$ after administration of the reference formulation. The mean (SD) $t 1 / 2$ was 7.13 (2.00) hours for the test formulation and 8.40 (6.17) hours for the reference formulation. The $90 \% \mathrm{Cls}$ of the ratios (test vs reference) for the natural $\log (\mathrm{ln})$-transformed $\mathrm{AUC}_{0-\mathrm{t}}, \mathrm{AUMC}_{0-\mathrm{t}}$ and $\mathrm{C}_{\max }$ are shown in Table 3. ANOVA assessment found no significant formulation, sequence, or period effect in the present study. The $90 \%$ CIs for the ratios of $\mathrm{AUC}_{0-\mathrm{t}}, \mathrm{AUMC}_{0-\mathrm{t}}$ and $\mathrm{C}_{\max }$ were $86.15 \%$ to $106.03 \%, 89.64$ 109.17 and $93.34 \%$ to $103.12 \%$ respectively, correlate the predetermined criteria for bioequivalence. The relative bioavailability of the test

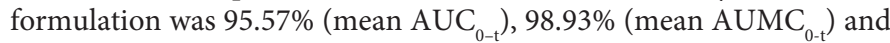
98.11\% (mean $\mathrm{C}_{\max }{ }^{\text {), }}$ respectively (Table 4).

The mean metformin plasma concentration time profiles after administration of the 2 formulations is shown in figure 2. Similarly, the mean (SD) $\mathrm{C}_{\max }$ value for metformin with the test formulation was $0.85(0.28) \mu \mathrm{g} . \mathrm{h} / \mathrm{ml}$, and the ${ }^{T \max }$ was $2.27(0.49)$ hours. With the reference formulation, the corresponding values were $0.90(0.28) \mu \mathrm{g} . \mathrm{h} /$ $\mathrm{ml}$ and $2.33(0.38)$ hours. The $\mathrm{t} 1 / 2$ values with the test and reference formulations were 57.78 (47.04) and 48.74 (36.17) hours, respectively (Table 3). No period or sequence effects were observed for the PK properties in the ANOVA. Statistical analysis showed that the $90 \%$ CIs for the ratio of $\mathrm{C}_{\max }(87.64 \%-100.85 \%), \mathrm{AUC}_{0-\mathrm{t}}(86.68 \%-116.15 \%)$ and $\mathrm{AUMC}_{0-\mathrm{t}}(92.07 \%-108.88 \%)$ values for the test and reference products fell within the established regulatory interval of $80 \%$ to $125 \%$ (Table 4 ). The mean relative bioavailabilities (test/reference) for $\mathrm{C}_{\max }, \mathrm{AUC}_{0-\mathrm{t}}$ and AUMC $_{0-\mathrm{t}}$ were $94.02 \%, 100.34 \%$ and $100.12 \%$ respectively.

\section{Discussion}

Evaluation of bioequivalence of generic product to innovator product is necessary to exclude any clinically important differences in the rate or extent at which the active entity of the drugs become 
Citation: Abbas M, Riffat S, Khan AM, Nawaz M (2011) Bioequivalence Evaluation of a Combine Formulation of Pioglitazone/Metformin in Healthy Pakistani Volunteers. J Bioequiv Availab 3: 092-096. doi:10.4172/jbb. 1000066

\begin{tabular}{|c|c|c|c|c|c|c|}
\hline \multirow[t]{2}{*}{ Parameters } & \multicolumn{2}{|l|}{ Test } & \multicolumn{2}{|l|}{ Reference } & \multicolumn{2}{|c|}{$P$ value } \\
\hline & $\mathrm{P}$ & M & $\mathrm{P}$ & M & $\mathrm{P}$ & M \\
\hline $\begin{array}{l}A \cup C(0-t)((\mu \mathrm{gh} / \mathrm{mL})) \\
\operatorname{A\cup C}(0-\infty)((\mu \mathrm{g} \mathrm{h} / \mathrm{mL}))\end{array}$ & $\begin{array}{l}3.13 \pm 1.03 \\
4.70 \pm 1.40\end{array}$ & $\begin{array}{l}7.26 \pm 3.72 \\
28.50 \pm 19.76\end{array}$ & $\begin{array}{l}3.28 \pm 1.08 \\
5.02 \pm 1.99\end{array}$ & $\begin{array}{l}7.33 \pm 4.04 \\
26.40 \pm 19.55\end{array}$ & $\begin{array}{l}0.23 \\
0.20\end{array}$ & $\begin{array}{l}0.45 \\
0.15\end{array}$ \\
\hline AUMC $(0-t)((\mu \mathrm{g} \mathrm{h} / \mathrm{mL}))$ & $17.58 \pm 12.15$ & $72.49 \pm 68.89$ & $19.98 \pm 14.54$ & $73.93 \pm 72.51$ & 0.20 & 0.46 \\
\hline $\operatorname{Cmax}(\mu \mathrm{g} / \mathrm{mL})$ & $0.41 \pm 0.07$ & $0.85 \pm 0.28$ & $0.42 \pm 0.06$ & $0.90 \pm 0.28$ & 0.26 & 0.05 \\
\hline $\operatorname{Tmax}(\mathrm{h})$ & $0.90 \pm 0.25$ & $2.27 \pm 0.49$ & $1.04 \pm 0.41$ & $2.33 \pm 0.38$ & 0.08 & 0.31 \\
\hline $\mathrm{t} 1 / 2(\mathrm{~h})$ & $7.13 \pm 2.00$ & $57.78 \pm 47.04$ & $8.40 \pm 6.17$ & $48.74 \pm 36.17$ & 0.16 & 0.11 \\
\hline MRT (h) & $10.94 \pm 2.79$ & $80.07 \pm 65.43$ & $12.54 \pm 7.89$ & $67.35 \pm 50.59$ & 0.16 & 0.11 \\
\hline
\end{tabular}

$\mathrm{P}=$ Pioglitazone, $\mathrm{M}=$ Metformin, $\mathrm{AUC}=$ Area under curve, $\mathrm{AUMC}=$ Area under moment curve, $\mathrm{Cmax}=$ maximal plasma concentration, Tmax $=$ time for the maximal plasma concentration, $t_{1 / 2}=$ Elimination half life, MRT = Mean residence time

Table 3: Pharmacokinetic parameters (mean \pm S.D. of $n=24$ ) of pioglitazone and Metformin after $15 / 850 \mathrm{mg}$ pioglitazone/metformin tablets based on its plasma concentrations.

\begin{tabular}{|l|l|l|l|l|}
\hline Parameter & \multicolumn{1}{|c|}{ Pioglitazone } & \multicolumn{2}{|c|}{ Metformin } \\
\hline & Ratio & $90 \% \mathrm{Cl}$ & Ratio & $90 \% \mathrm{Cl}$ \\
\hline Ln AUC0-t & 95.57 & $86.15-106.03$ & 100.34 & $86.68-116.15$ \\
\hline Ln AUC0- $\infty$ & 95.90 & $85.62-107.41$ & 110.07 & $94.14-122.71$ \\
\hline Ln AUMC0-t & 98.93 & $89.64-109.17$ & 100.12 & $92.07-108.88$ \\
\hline Ln Cmax & 98.11 & $93.34-103.12$ & 94.02 & $87.64-100.85$ \\
\hline
\end{tabular}

Table 4: Comparison of $90 \% \mathrm{Cls}$ of natural log (In)-transformed parameters for two formulations (test/reference) of pioglitazone/metformin in healthy Pakistani male volunteers.

available at the site of action. Two formulations are considered to be bioequivalent if they are pharmaceutically equivalent and their bioavailability is so similar that they are unlikely to produce clinically relevant differences regarding the safety and efficacy of drug [12]. The purpose of the present study was to compare the bioavailability of 2 formulations of pioglitazone/metformin 15/850 mg tablets, a locally manufactured (test) formulation, Piozer Plus (Hilton Pharm., Karachi), and a reference formulation, Competact (Takeda Inst., Japan).

All pharmacokinetic parameters of pioglitazone derived using the non-compartmental method was found to be similar for both formulations. The test and reference formulations exhibited overlapping plasma profiles indicated that the 2 formulations were similar in both absorption as well as in elimination, (Figure 2). The $\mathrm{AUC}_{0-\mathrm{t}}$, $\mathrm{AUMC}_{0-\mathrm{t}}$ and $\mathrm{C}_{\max }$ values acquired with the generic and innovator formulations were not significantly different, which reflects the similar PK characteristics of the 2 formulations. However, in this study, the mean $\mathrm{AUC}_{0-\mathrm{t}}$ value of both test and reference drugs were lower than those found in a previous studies [13-15], following administration of a 30mg pioglitazone tablet and comparable to a study [16], following administration of $15 \mathrm{mg}$ pioglitazone. Moreover, in the present study the $\mathrm{C}_{\max }$ and $\mathrm{T}_{\max }$ values of both test and reference formulations were comparable to previous studies [13-15], though their dosage vary as $30 \mathrm{mg}$ pioglitazone tablet and $15 \mathrm{mg}$ pioglitazone tablet [16]. The $90 \%$ CIs for the natural log-transformed $\mathrm{AUC}_{0-\mathrm{t}}, \mathrm{AUMC}_{0-\mathrm{t}}$ and $\mathrm{C}_{\max }$ values were well within the bioequivalence range of 0.8 to 1.25 , therefore the 2 formulations can be considered bioequivalent according to the bioequivalence guidence with respect to the extent of absorption [12].

The mean plasma concentration-time curves of 2 formulations of metformin after a single oral dose of $15 / 850 \mathrm{mg}$ of either test or reference formulation of pioglitazone/metformin was recorded almost same during the entire period (Figure 2). Both formulations were apparently readily absorbed, and metformin was measurable at 0.25 hour. The mean $\mathrm{AUC}_{0-\mathrm{t}}, \mathrm{AUMC}_{0-\mathrm{t}}, \mathrm{C}_{\max }$ and $\mathrm{T}_{\max }$ values with the test formulation were numerically lower but not statistically significant from those with the reference formulation, agreed with the previous studies [17-22]. However, the mean half life value with the test formulation was numerically higher but not statistically significant from that with the reference formulation. Pharmacokinetic parameters when analyzed using ANOVA, statistically non significant differences were observed between the 2 formulations in the logarithmically transformed $\mathrm{AUC}_{0-\mathrm{t}}$ or $\mathrm{C}_{\max }$ also ANOVA found no period or sequence effects for any pharmacokinetic property. The absence of a sequence effect in both parameters suggests that there was no carryover effect. However, further research work is necessary to carry out such studies in female volunteers as well as in patients to make a better conclusion.

\section{Conclusions}

It is concluded that both the test and reference formulations (containing two drugs pioglitazone and metformin 15/850 mg tablets) met the acceptance criteria for bioequivalence based on the rate and extent of absorption. Both formulations were well tolerated by young healthy volunteers.

\section{Acknowledgments}

This work was supported by a research grant of Bioequivalence Study (BeSt) Centre, Institute of Pharmaceutical Sciences, University of Veterinary and Anima Sciences (UVAS). The authors would like to thank the investigator and the subjects who participated in this study.

\section{References}

1. Lebovitz HE (2004) Oral antidiabetic agents. Med Clin North Am 88: 847-863.

2. Bell DS (2004) Type 2 diabetes mellitus: what is the optimal treatment regimen?sss Am J Med, 116: 23S-29S.

3. Horton ES, Clinkingbeard C, Gatlin M, Foley J, Mallows S et al. (2000) Nateglinide alone and in combination with metformin improves glycemic contro by reducing mealtime glucose levels in type 2 diabetes. Diab Care 23: 1660 1665.

4. Hirschberg Y, Karara AH, Pietri AO,McLeod JE (2000) Improved control of mealtime glucose excursions with coadministration of nateglinide and metformin. Diab Care 23: 349-353.

5. Rendell MS, Glazer NB, Ye Z (2003) Combination therapy with pioglitazone plus metformin or sulfonylurea in patients with Type 2 diabetes: influence of prior antidiabetic drug regimen. J Diab Compl 17: 211-217.

6. Riddle M (2000) Combining sulfonylureas and other oral agents. Am J Med 108: $15 \mathrm{~S}-22 \mathrm{~S}$

7. Dailey GE (2003) Glyburide/metformin tablets: a new therapeutic option for the management of Type 2 diabetes. Expert Opin Pharmaco 4: 1417-1430. 
Citation: Abbas M, Riffat S, Khan AM, Nawaz M (2011) Bioequivalence Evaluation of a Combine Formulation of Pioglitazone/Metformin in Healthy Pakistani Volunteers. J Bioequiv Availab 3: 092-096. doi:10.4172/jbb.1000066

8. Funnell MM, Kruger DF (2004) Type 2 diabetes: treat to target. Nurse Pract 29:11-23.

9. Pattana S, Penporn N, Aurasorn S (2006) High-performance liquid chromatographic method for the determination of pioglitazone in human plasma using ultraviolet detection and its application to a pharmacokinetic study. Journal of Chromatography B 843: 164-169.

10. Valentina P, Simone GS, Eunice KK, Eunice EK, Yara PA, et al. (2008) HPLC-UV determination of metformin in human plasma for application in pharmacokinetics and bioequivalence studies. J Pharmaceutical and Biomedical Analysis 46: 143-147.

11. FDA/ICH, (CDER and CBER), Q7A (2001) Good Manufacturing Practice, Guidance for Active Pharmaceutical Ingredients, ICH guidance for industry.

12. US Food and Drug Administration. Definition of bioequivalence, http://www.fda gov/cder/ogd/02-10_BCBS_gjb/sld028.htm. Accessed May 2, 2007.

13. Sripalakit P, Neamhom P, Saraphanchotiwitthay A (2006) High-performance liquid chromatographic method for the determination of pioglitazone in human plasma using ultraviolet detection and its application to a pharmacokinetic study. Journal of Chromatography B 843: 164-169.

14. Wittayalertpanya S, Chompootaweep S, Thaworn N (2006) The Pharmacokinetics of Pioglitazone in Thai Healthy Subjects. J Med Assoc Thai 89: 2116-2122.

15. Zhang H, Wang X, Zhang X, Zhang Q, Li K (2004) Study on bioequivalence of pioglitazone hydrochloride tablets in healthy Chinese volunteers. Asian Journal of Drug Metabolism and Pharmacokinetics 4: 119-122.
16. Xue YJ, Turner KC, Meeker JB, Pursley J, Arnold M, et al. (2003) Quantitative determination of pioglitazone in human serum by direct-injection highperformance liquid chromatography mass spectrometry and its application to a bioequivalence study. Journal of Chromatography B 795: 215-226.

17. Mistri HN, Jangid AG, Shrivastav PS (2007) Liquid chromatography tandem mass spectrometry method for simultaneous determination of antidiabetic drugs metformin and glyburide in human plasma. Journal of Pharmaceutical and Biomedical Analysis 45: 97-106.

18. Wang Y, Tang Y, Gua J, Fawcett JP, Bai X (2004) Rapid and sensitive liquid chromatography tandem mass spectrometric method for the quantitation of metformin in human plasma. J Chromatography B 808: 215-219.

19. Marlice A, Marques S, Soares ADS, Pinto OW, Barroso PTW, et al. (2007) Simple and rapid method determination for metformin in human plasma using high performance liquid chromatography tandem mass spectrometry: Application to pharmacokinetic studies. Journal of Chromatography B 852 : 308-316.

20. Zarghi A, Foroutan SM, Shafaati A, Khoddam A (2003) Rapid determination of metformin in human plasma using ion-pair HPLC. Journal of Pharmaceutical and Biomedical Analysis 31: 197-200.

21. Chen X, Gu Q, Qiu F, Zhong D (2004) Rapid determination of metformin in human plasma by liquid chromatography-tandem mass spectrometry method. Journal of Chromatography B 802: 377-381.

22. Bhavesh D, Chetan G, Bhat KM, Shivprakash (2007) Estimation and pharmacokinetics of metformin in human volunteers. Indian J Pharm Educ Res 41. 